\title{
Correction to: NASA Formal Methods
}

\author{
Ritchie Lee (1D), Susmit Jha (D), Anastasia Mavridou (D), \\ and Dimitra Giannakopoulou
}

\section{Correction to: \\ R. Lee et al. (Eds.): NASA Formal Methods, LNCS 12229, https://doi.org/10.1007/978-3-030-55754-6}

The original versions of this book and Chapter 14 were revised. The following was corrected:

Dimitra Giannakopoulou, the General Chair of the NFM 2020 conference, was inadvertently forgotten and, therefore, added as a volume editor.

Chapter 14 was retrospectively made available open access under a CC BY 4.0 license at link.springer.com.

The updated version of the book can be found at https://doi.org/10.1007/978-3-030-55754-6_14 https://doi.org/10.1007/978-3-030-55754-6

(C) The Author(s) 2020

R. Lee et al. (Eds.): NFM 2020, LNCS 12229, p. C1, 2020.

https://doi.org/10.1007/978-3-030-55754-6_26 